\title{
Prognosis and possible presymptomatic manifestations of congestive cardiomyopathy (COCM)*
}

\author{
HORST KUHN \\ M.D. \\ HANS-JÜRGEN KNIERIEM
M.D. \\ BENNO LÖSSE \\ M.D.
}

\author{
GÜNTER BREITHARDT \\ M.D. \\ EKKEHART KÖHLER \\ M.D. \\ LUDGER SEIPEL \\ M.D.
}

\section{Franz LoOGEN \\ M.D.}

\author{
Medical Hospital B, University of Düsseldorf, West Germany
}

\begin{abstract}
Summary
In order to find evidence of prognosis and of presymptomatic manifestation of congestive cardiomyopathy (COCM) in fifty-eight patients, the extent of morphological changes of endomyocardial catheter biopsy (EMCB), clinical and haemodynamic data were correlated to the clinical course. In addition, clinical, haemodynamic, angiographic, morphological and His-bundle electrographic studies were performed in patients with left bundle branch block (LBBB), normal left ventricular end-diastolic volume, and normal coronary arteries $(n=43)$.

Related to a 10-year mortality rate of $70 \%$ from the onset of symptoms, COCM is one of the most severe heart diseases. Endomyocardial catheter biopsy (EMCB) allowed clear prognostic separation in patients with COCM and seems to be of diagnostic value in patients with only slightly enlarged hearts and in patients with a short history of symptoms. The studies also revealed much evidence that at least some patients with LBBB, normal left ventricular enddiastolic volume (LVEDV) and normal coronary arteries exhibit an early stage of COCM. In these patients especially EMCB with severe changes of heart muscle cells and/or impaired left ventricular function may indicate subsequent COCM. So that there is now a new indication for performing EMCB.
\end{abstract}

\section{Introduction}

The clinical course of patients with congestive cardiomyopathy can vary considerably, i.e. it can be fast or slow or may even show transient remission (Breithardt, Kuhn and Knieriem, 1978; Kuhn et al.,

\footnotetext{
* Supported in part by grant of Deutsche Forschungsgemeinschaft, SFB 30 Kardiologie Düsseldorf.

Correspondence: Dr H. Kuhn, Medizinische Klinik B der Universität, Moorenstr. 5, D-4 Düsseldorf, West Germany.
}

1975; Oakley, 1974; Stapleton, Segal and Harvey, $1970,1974)$. The diagnosis of COCM is mostly made in an advanced stage of the disease, as the presymptomatic manifestation of COCM is unclear. Therefore, following previous studies (Kuhn et al., 1974a, 1975, 1978; Loogen and Kuhn, 1977; Breithardt et al., 1978) endomyocardial catheter biopsy (EMCB) was used in an attempt to get more information on prognosis of COCM. Clinical and haemodynamic data as well as biopsy results were correlated to the clinical course of the patients.

Former studies in a small number of patients gave some evidence for presymptomatic manifestation of COCM in patients with complete left bundle branch block (LBBB) (Kuhn et al., 1978). Now in a larger group of patients with LBBB of unknown aetiology, different investigations were performed, including haemodynamic and angiographic measurements, EMCB, His-bundle-electrography (His-BE) and estimation of minimal cardiac transit times (MTT) in order to find evidence for subsequent COCM.

\section{Patients and methods}

Fifty-eight patients with COCM (Goodwin and Oakley, 1972; Kuhn et al., 1973, 1978), in whom EMCB could be performed, were studied. Biopsies were taken from the right ventricle, the right and left heart were catheterized, left ventricular ciné angiogram, coronary arteriography, chest X-ray, ECG, phonocardiogram, apexcardiogram, external carotid pulse tracing and laboratory tests were carried out. Left ventricular ciné angiograms, left ventricular end-diastolic volume (LVEDV) and left ventricular end-systolic volume (LVESV) were estimated from mono-planes using the area length method. From these data, indices were derived yielding LVEDVI and LVESVI (unit: volume $/ \mathrm{m}^{2}$ 


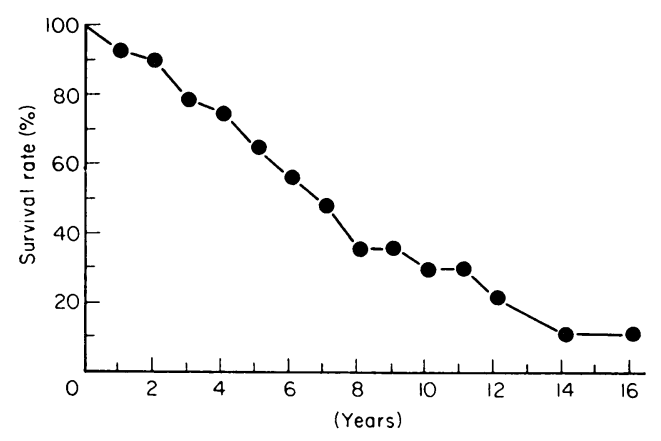

Fig. 1. Cumulative survival rate in fifty-eight patients with COCM from the onset of illness to the end of the observation period.

surface area), and ejection fraction (EF, \%) was calculated. The teleroentgenogram in posterior anterior projection was used for estimation of cardiothoracic ratio (CT-ratio). Right ventricular EMCB was performed by transfemoral approach using either the Konnobioptome or a modified bronchus bioptome (Key-med England, or Pflugbeil, WestGermany). No severe complications were observed in these, or any others $(n=219)$, patients in the Düsseldorf hospital from whom biopsies had been taken (Kuhn et al., 1978). Generally one or three specimens were taken for both light- and electronmicroscopic examination (Kuhn et al., 1975). Morphological aspects were assessed from semi-thin and ultra-thin sections by workers without knowledge of the clinical data. In addition semi-quantitative morphological evaluation was done. The morphological picture was estimated according to the frequency, extent and severity of alterations using a semiquantitative morphological score already applied in earlier works (Table 2). The following were considered to be degenerative changes: increased number of myelin figures, lipid droplets or lipofuscine granules, proliferation of sarcoplasmic reticulum, lysosomal changes, lysis of myofilaments and abnormal configurated mitochondria with abnormal variation in size. Degenerative changes in general were regarded as severe when there were at least three of them. Changes in the mitochondria included mitochondriosis and abnormally large or small mitochondria. Myofibrillar changes were considered as being present in cases of abnormal arrangement of myofibres and myofibrils running in adverse directions, abnormal thickening or irregularity of Z-bands. Interstitial fibrosis was evaluated from semi-thin sections. Myocardial hypertrophy was classified according to the size of the myofibres: slight $(15-20 \mu)$, moderate $(21-25 \mu)$ and severe $(\geqslant 26 \mu)$.

All patients were examined at regular intervals of 6-12 months in the out-patient clinic. All patients

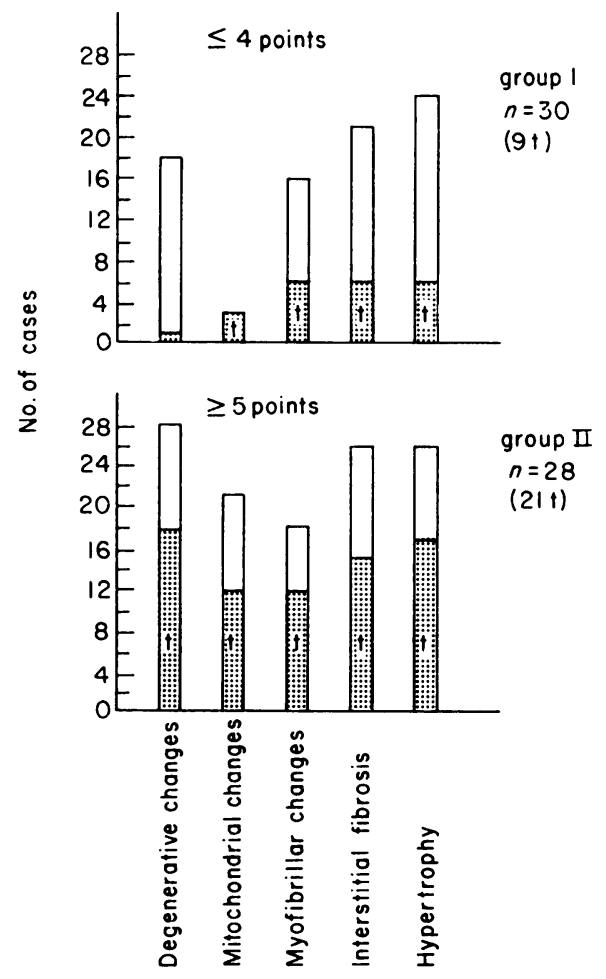

FIG. 2. Ultrastructural changes in fifty-eight patients with COCM. Data are grouped according to the morphological score. Deceased patients are indicated by shading.

were followed-up. December 30, 1977 was taken as the date for determining the outcome of each case. His-BE was performed according to the technique of Scherlag et al. (1969) with a special $4 \mathrm{~F}$ bipolar catheter for single use (Cordis).

Studies in patients with LBBB (without COCM): Forty-three consecutive patients with LBBB and normal LVEDV were studied applying the same diagnostic procedure as in patients with COCM. In addition, mean pulmonary artery pressure (MPAP) was measured at exercise which was increased every 3 min using a Swan Ganz catheter. MPAP on exercise correlates best with LVEDP according to measurements of Bonzel et al. (1976). According to the result of MPAP measurement, patients with LBBB were subdivided into patients with latent cardiomyopathy (LCM) and other patients, in whom LBBB was the only pathological finding. LCM was defined by normal thickness of septum and posterior wall of left ventricle measured by the M-mode echocardiography (Echopan, Siemens), normal LVEDV and normal EF, no outflow-tract obstruction of left ventricle, but with elevated 
LVEDP at rest or in most cases on exercise, demonstrated by abnormally high MPAP, i.e. $>30 \mathrm{mmHg}$ at $60 \mathrm{~W}$ (normal values, see Haerten et al., 1976). MTT were measured using ${ }^{113 \mathrm{~m} I n}$ before and at the end of ergometric work (Vyska et al., 1975; Lösse and Loogen, 1978).

The following definitions were used: (1) Duration of illness is the interval from the onset of symptoms to the date of myocardial biopsy. (2) Follow-up period is the interval from the date of myocardial biopsy to December 30,1977. (3) Survival period is the interval from the date of biopsy to the death of the patient or, when still alive, to December 30, 1977.

Statistical analysis was applied using the Wilcoxon test. Cumulative survival rates were calculated with the method of Cutter and Ederer (1958).

\section{Results}

Mean age of all patients was $\mathbf{4 2}$ years, mean duration of illness before biopsy was $3 \cdot 5$ years (maximum 16 years, minimum 0.3 years) and mean survival period and follow-up period were 1.5 years and $2 \cdot 6$ years respectively.

Figure 1 shows the cumulative survival rate of fifty-eight patients with COCM from the onset of illness to December 30, 1977 or the date of death. The 5-year survival rate was $65 \%$, whereas the 10 -year survival rate was only $30 \%$.

The frequency and the extent of myocardial ultrastructural lesions varied. Myocardial hypertrophy, interstitial fibrosis and degenerative changes were the most frequently seen (Fig. 2). Patients were divided according to their morphological score (Table 2, Fig. 2). Group I $(n=30)$ consisted of those patients with $\leqslant 4$ points, group II $(n=28)$ of those with $\geqslant 5$ points. In both groups hypertrophy, interstitial fibrosis and myofibrillar changes were seen with near-equal frequency (Fig. 2). However, alterations of mitochondria were observed in only three patients in group I and 21 in group II. Degenerative changes occurred in all patients of group

TABLE 1. Clinical data and mortality in fifty-eight patients with COCM. Patients are grouped according to the extent of pathological changes

\begin{tabular}{lcc}
\hline Morphological score & $\leqslant 4$ points & $\geqslant 5$ points \\
\hline No. of patients & 30 & 28 \\
Age (mean) & $39 \cdot 1 \pm 9 \cdot 1$ & $42 \cdot 7 \pm 9 \cdot 0$ years \\
Duration of illness & $3 \cdot 8 \pm 3 \cdot 5$ & $3 \cdot 1 \pm 2 \cdot 6$ years \\
Cardio-thoracic ratio & $0 \cdot 554 \pm 0 \cdot 07$ & $0 \cdot 595 \pm 0 \cdot 05$ \\
EF & $38 \cdot 7 \pm 15 \cdot 1$ & $34 \cdot 2 \pm 14 \cdot 0 \%$ \\
EDVI & $140 \cdot 3 \pm 30 \cdot 9$ & $176 \cdot 0 \pm 61.0 \mathrm{ml} / \mathrm{m}^{2}$ \\
Follow-up period & $2 \cdot 5 \pm 2 \cdot 7$ & $2 \cdot 7 \pm 1 \cdot 3$ years \\
Survival period & $1.9 \pm 1 \cdot 0$ & $1 \cdot 1 \pm 0 \cdot 8$ years \\
Score (mean) & $3.0 \pm 1.0$ & $6 \cdot 3 \pm 1 \cdot 2$ \\
Mortality & $30 \%$ & $75 \%$ \\
\hline
\end{tabular}

TABLE 2. Morphological score for semi-quantitative evaluation of myocardial biopsies

\begin{tabular}{llc}
\hline \multirow{2}{*}{ 1. Degenerative changes } & Points \\
& $\begin{array}{l}\text { rare-slight } \\
\text { frequent-severe }\end{array}$ & 1 \\
2. Mitochondrial changes & rare & 1 \\
& frequent & 2 \\
3. Myofibrillar changes & rare & 1 \\
& frequent & 2 \\
4. Interstitial fibrosis & moderate & 1 \\
5. Hypertrophy & severe & 2 \\
& slight & 1 \\
& moderate & 2 \\
& severe & 3 \\
\hline
\end{tabular}

II compared to eighteen in group I. Mortality was very high in group II $(21$ of $28,75 \%)$ and low in group I (nine of thirty, $30 \%$ ). Clinical and haemodynamic data were not significantly different in these two groups (Table 1) although CT-ratio and LVEDVI tended to be greater and EF tended to be lower in group II. The cumulative survival rate was lower at all intervals of follow-up in group II (Fig. 3). Survival rate after 4 years was $0 \%$ in group I and $54 \%$ in group II.

The prognostic significance of other parameters was tested by grouping the patients according to their final outcome regardless of the morphological score (Fig. 5). Mean age and duration of illness were not significantly different when comparing those patients who died with those who survived. Survival period, follow-up period, morphological score, CTratio, LVEDVI and EF were significantly different. The scatter of individual data was highest in LVEDVI and EF. To test the relation between the extent of morphological changes and the duration of the illness, the morphological score was compared to the duration of illness and to its outcome (Fig. 4). As can be seen, there was no positive correlation between the two. However, when focusing on those

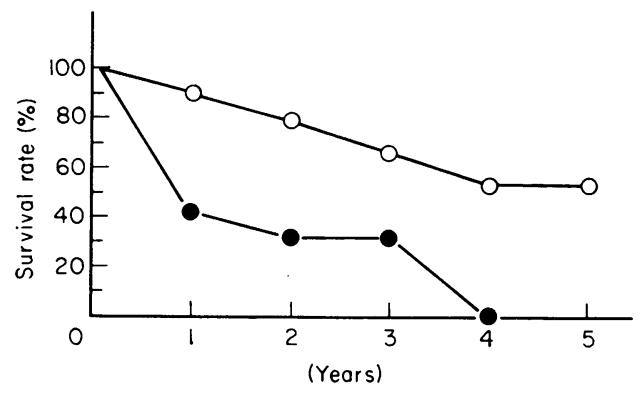

FIG. 3. Cumulative survival rate in fifty-eight patients with COCM from the date of biopsy according to the morphological score. $0-0 \leqslant 4$ points. $\longrightarrow 5$ points. 


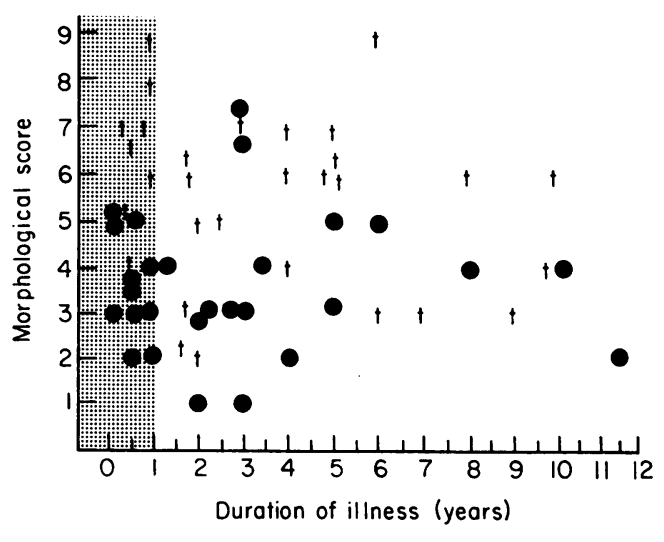

Fig. 4. A plot of the morphological score versus the duration of illness before biopsy in fifty-eight patients with COCM. Deceased patients are indicated by crosses.

patients with a duration of illness $\leqslant 2$ years $(n=27)$, the survival could be predicted with a relatively high degree of accuracy by the morphological score. Only four patients with $\leqslant 4$ points died out of fourteen patients (age $37 \pm 10$ years, duration of illness $1.2 \pm 0.8$ years, follow-up period $2.6 \pm 1.2$ years), whereas ten of thirteen patients in the other group died ( $\geqslant 5$ points). CT-ratio in these two groups was $0.569 \pm 0.065$ and $0.602 \pm 0.059$; EF was $40.8 \pm 5.9$ and $34.3 \pm 16.3 \%$; EDVI was $136.9 \pm 31.9$ and $180 \cdot 1 \pm 64 \cdot 2 \mathrm{ml} / \mathrm{m}^{2}$ respectively. Two-year cumulative mortality rate was $14 \%$ and $77 \%$ respectively. These differences were even more pronounced when focusing on those patients with a duration of illness of $\leqslant 1$ year. Only one of nine patients died with $\leqslant 4$ points, whereas seven of ten patients with $\geqslant 5$ points (Fig. 4) died. The differences in CT-ratio,
LVEDVI, EF, duration of illness and follow-up period were not statistically significant.

Different observations were made indicating a possible pre-stage of COCM in patients with LBBB, which occurs in nearly $40 \%$ of these patients (Table 5). One of them was the result of retrospective study, i.e. LBBB in COCM was documented or described many years before the clinical onset of COCM (Kuhn et al., 1978) (Table 3). To date, this ECG abnormality has been found in thirteen patients with COCM and common LBBB (criteria of the New York Heart Assocation), i.e. in one case as far back as 22 years, in six cases 8-16 years. In nine cases normal heart size was seen before the onset of symptoms (mostly dyspnoea) possibly indicative of COCM. In four patients $(+$, Table 3$)$ transient uncharacteristic heart pains were the cause for performing an ECG. Some patients could not remember the cause, others mentioned routine examinations because of different reasons. One cannot ignore the fact that the left ventricle was dilated in these patients in spite of their hearts being of normal size. This is supported by the findings in 55 consecutive patients with LBBB of unknown cause, with a normal heart size and normal coronary arteries (EDVI $113 \pm 6 \mathrm{ml} / \mathrm{m}^{2}\left(\bar{x} \pm s_{x}\right)$ ). Seven of these had a dilated left ventricle. There were 2 cases of hypertropic non-obstructive cardiomyopathy (HNCM, ASH) detected by M-mode echocardiography (IVS/PW ratio, $18: 11$ and $22: 16$ respectively). To find evidence for possible early manifestation of COCM in the remaining patients with LBBB $\left(n=43\right.$, EDVI $\left.78 \pm 16 \mathrm{ml} / \mathrm{m}^{2}\right)$ different studies were performed, i.e. measurement of MPAP at rest and at exercise , EMCB, His-BE and estimation of MTT.

Mean age in these patients was as high (42 years)

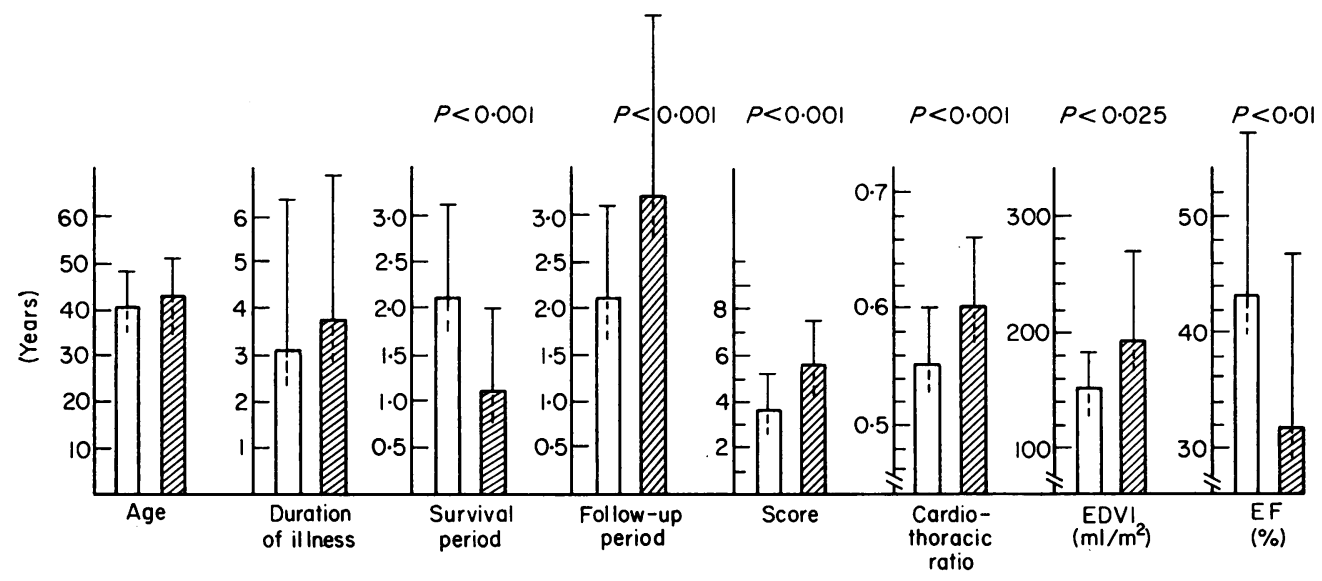

:FIG. 5. Clinical and haemodynamic data and morphological score in fifty-eight patients with COCM (mean \pm s.d.). $\square$ alive $(n=28)$. 
Prognosis and presymptomatic manifestations of COCM

TABLE 3. LBBB in thirteen patients with COCM before the onset of signs symptomatic of COCM

\begin{tabular}{|c|c|c|c|c|c|c|c|}
\hline \multirow[b]{2}{*}{ Patient } & \multirow{2}{*}{$\begin{array}{c}\text { Age } \\
\text { (years) }\end{array}$} & \multirow[b]{2}{*}{ Sex } & \multirow{2}{*}{$\begin{array}{l}\text { Before } \\
\text { COCM } \\
\text { (years) }\end{array}$} & \multirow{2}{*}{$\begin{array}{c}\text { Cardiac } \\
\text { complaints }\end{array}$} & \multicolumn{2}{|c|}{ CT-ratio } & \multirow{2}{*}{$\begin{array}{c}\text { Duration } \\
\text { of COCM } \\
\text { (years) }\end{array}$} \\
\hline & & & & & Before COCM & After COCM & \\
\hline P.W. & 40 & $\mathrm{~m}$ & $3 \cdot 5$ & - & $(<0.500)$ & 0.560 & 6 \\
\hline V.F. & 40 & $\mathrm{~m}$ & 13 & - & 0.478 & 0.651 & 2 \\
\hline S.W. & 57 & $\mathrm{~m}$ & 3 & $(+)$ & 0.462 & 0.600 & 7 \\
\hline L.W. & 47 & f & 8 & - & & 0.540 & 6 \\
\hline P.H. & 53 & $\mathrm{~m}$ & $2 \cdot 5$ & - & 0.498 & 0.594 & $2 \cdot 5$ \\
\hline W.H. & 49 & m & 2 & - & $(<0.500)$ & 0.617 & 8 \\
\hline L.E. & 49 & f & 5 & $(+)$ & 0.434 & 0.520 & 3 \\
\hline T.H. & 51 & f & 22 & - & 0.470 & 0.630 & 0.5 \\
\hline K.J & 48 & m & 14 & - & 0.430 & 0.540 & 2 \\
\hline S.G. & 38 & $\mathrm{~m}$ & 9 & - & & 0.530 & 2 \\
\hline V.P. & 67 & m & 11 & $(+)$ & $(<0.500)$ & 0.620 & 4 \\
\hline S.E. & 53 & $\mathrm{~m}$ & 16 & $(+)$ & & & 3 \\
\hline D.F. & 48 & $\mathrm{~m}$ & 10 & - & & 0.490 & 2 \\
\hline
\end{tabular}

TABLE 4. Age (mean and range) in patients with COCM and in patients with LBBB without COCM. MPAP $\uparrow=$ elevated mean pulmonary artery pressure, $\mathbf{L C M}=$ latent cardiomyopathy

\begin{tabular}{|c|c|c|}
\hline $\begin{array}{l}\text { COCM total } \\
\text { without LBBB } \\
\text { with LBBB }\end{array}$ & $\begin{array}{c}\text { Years } \\
42(17-67) \\
40(17-59) \\
47(27-67)\end{array}$ & $\left.\begin{array}{l}n=151 \\
n=97 \\
n=54\end{array}\right\} P<0.001$ \\
\hline $\begin{array}{l}\text { LBBB total } \\
\text { unknown (MPAP }\end{array}$ & $43(28-61)$ & $n=43$ \\
\hline $\begin{array}{c}\text { normal) } \\
\text { LCM (MPAP } \uparrow)\end{array}$ & $\begin{array}{ll}38 & (28-55) \\
48 & (31-61)\end{array}$ & $\left.\begin{array}{l}n=17 \\
n=26\end{array}\right\} P<0.001$ \\
\hline
\end{tabular}

as in patients with COCM (43 years) but was lower when patients with COCM and LBBB (47 years) were compared with a wide range of age (28-61 and 27-67 years respectively) (Table 4). Distribution of sex showed prevalence among men in COCM with LBBB $(60 \%$, total $n=54)$ and among women in LBBB without COCM $(53 \%$, total $n=43)$. The difference between mean age of COCM patients with and without LBBB was highly significant (Table 4).

In Fig. 6 MPAP at rest and at exercise is shown. As can be seen in twenty-six of forty-three patients an abnormal elevation of MPAP was found indicating latent left heart failure. Also the total of patients with LBBB $(n=43)$ showed a significantly higher elevation of MPAP under exercise than was found in normal subjects. For the patients with abnormal elevated MPAP the diagnostic designation 'latent cardiomyopathy (LCM)' is proposed (Kuhn et al., 1978). Mean age of these patients with LCM (48 years) was significantly higher than in patients with LBBB and normal MPAP ('LBBB unknown group') (38 years), the scatter being again very great (Table 4). LVEDP at rest, EDVI and EF were normal and not significantly different although EF was somewhat lower in patients with LCM. Aortic pressure showed a slight elevation (Fig. 7a and b).

In twenty-one patients with LBBB and normal LVEDV right ventricular EMCB and both lightand electronmicroscopic examination of specimens were done (Fig. 8). In nineteen patients abnormal findings were seen. In five patients even severe alterations of myocardial cells were present. Examples are shown in former work (Kuhn et al., 1978). For semi-quantitative evaluation the same morphological score was applied as in patients with COCM (Table 2). Changes are summarized in Fig. 8, including degenerative, mitochondrial and myofibrillar alterations, interstitial fibrosis and hypertrophy. Myofibrillar changes were rare in the 'LBBB unknown group' and more frequent in patients with LCM. Degenerative changes were more frequent in LCM.

TABLE 5. HV-interval in patients with LBBB and in normal subjects (mean \pm s.d.)

\begin{tabular}{|c|c|c|c|c|c|c|}
\hline \multirow[b]{2}{*}{ Aetiology of LBBB } & \multicolumn{2}{|c|}{$\mathrm{H}-\mathrm{V}$ normal } & \multicolumn{2}{|c|}{$\mathrm{H}-\mathrm{V}$ prolonged } & \multicolumn{2}{|c|}{ Total } \\
\hline & $n$ & $\mathrm{H}-\mathrm{V} \mathrm{ms}$ & $n$ & H-V ms & $n$ & $\mathrm{H}-\mathrm{V} \mathrm{ms}$ \\
\hline $\mathrm{COCM}$ & 3 & $55 \pm 0.7$ & 24 & $78 \pm 26$ & 27 & $79 \pm 28$ \\
\hline Other: total & 10 & $50 \pm 10$ & 23 & $68 \pm 10$ & 32 & $63 \pm 12$ \\
\hline LCM & 5 & $50 \pm 4$ & 8 & $68 \pm 11$ & 13 & $61 \pm 13$ \\
\hline unknown & 4 & $50 \pm 5$ & 15 & $69 \pm 10$ & 19 & $64 \pm 12$ \\
\hline Normal & & & & & 51 & $43 \pm 6.9$ \\
\hline
\end{tabular}

$*=P<0.005$ 


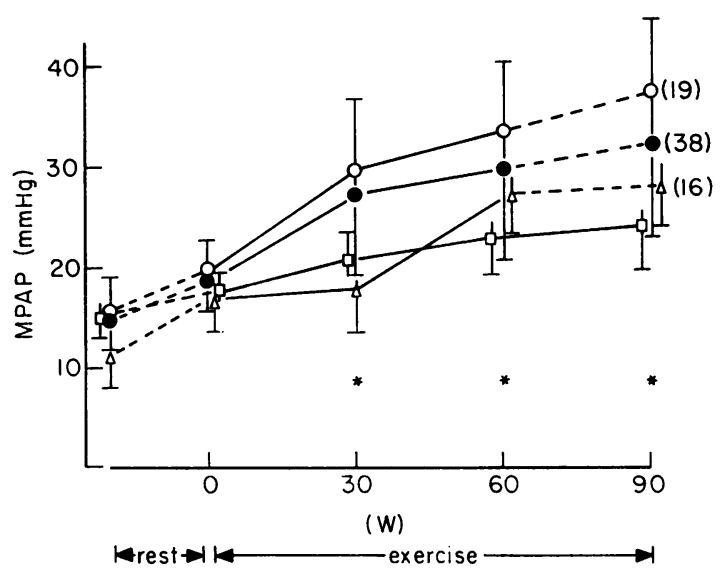

Fig. 6. Mean pulmonary artery pressure at rest and during exercise in patients with left bundle branch block (LBBB) and in normal subjects (mean \pm s.d.) $(*=P<0.005$ ). LBBB (total) $n=43$. O LBBB (LCM) $n=26$. $\triangle$ LBBB (unknown) $n=17$. $\square$ Normal $n=30$. LCM = latent cardiomyopathy.
The extent of changes as expressed by morphological points was also higher in LCM, but this difference was not significant. Severe changes ( $\geqslant 5$ points) were present in five patients, three of them being in the 'LBBB unknown' group.

In Table 5 the result of His-BE as related to normal and abnormal HV-intervals in patients with COCM and in the two LBBB groups is shown. A high incidence of prolonged $\mathrm{HV}$-time was found in patients with COCM (23) and in both LBBB groups (24). The longest time-values were seen in COCM, the mean value being significantly higher in this group than in the LBBB group. HV-time in LCM and in the 'LBBB unknown' group was nearly identical and significantly longer than in normal subjects. MTT was measured in a relatively small group of fourteen patients with LBBB and normal LVEDV. Abnormal prolongation could be seen in $21 \%$ $(\bar{x}=4 \cdot 15 \mathrm{sec}$, range $3.9-4.62 \mathrm{sec}$, normal value $2 \cdot 8 \pm 0.5 \mathrm{sec})\left(\bar{x} \pm s_{x}\right)$. The rate of an abnormally elevated MPAP in the same patients at exercise was

\footnotetext{
LBBB (total) $n=43$

$\square$ LBBB (LCM) $n=26$

LBBB (unknown) $n=17$

Normal $n=7$
}
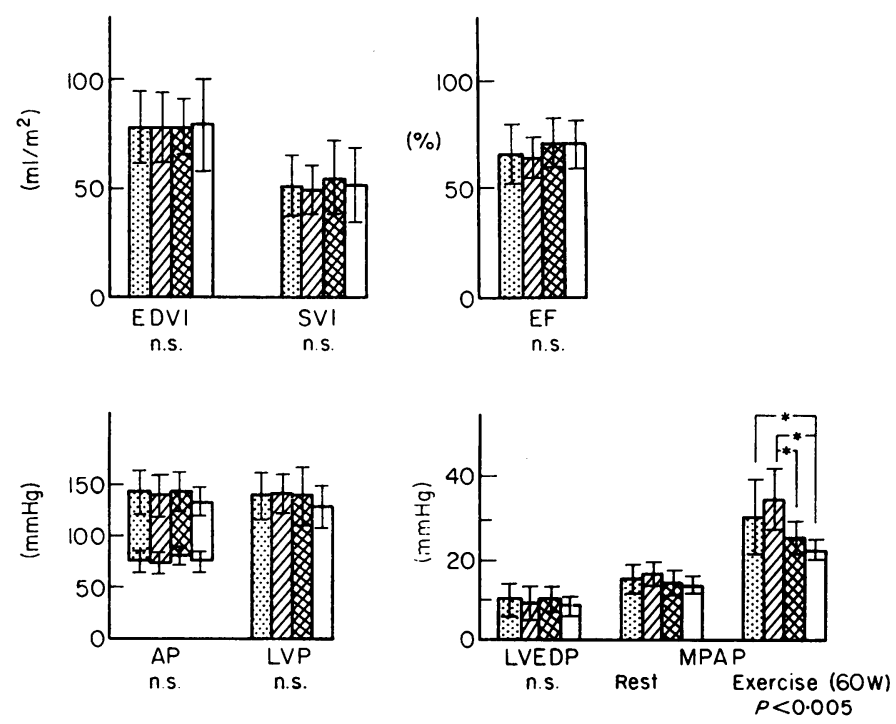

FIG. 7. Angiographic and haemodynamic findings in patients with left bundle branch block (LBBB) and in normal subjects. EDVI = end-diastolic volume index, $S V I=$ stroke volume index, $E F=$ ejection fraction of left ventricle, $\mathbf{A P}=$ aortic pressure, $\mathbf{L V P}=$ left ventricular peak pressure, LVEDP $=$ left ventricular end-diastolic pressure, MPAP $=$ mean pulmonary artery pressure $($ mean \pm s.d.) $\mathbf{L C M}=$ latent cardiomyopathy. n.s. $=$ not significant, ${ }^{*}=P<0.005$. 

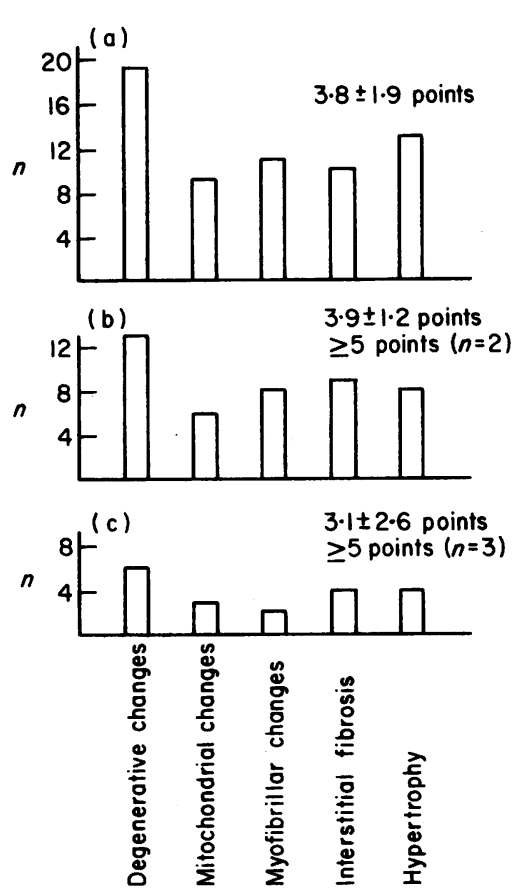

FIG. 8. Frequency of morphological findings and morphological score in twenty-one patients with left bundle branch block (LBBB) (mean \pm s.d.) $n=$ number of patients. (a) LBBB total $(n=21)$. (b) LBBB LCM $(n=13)$. (c) LBBB unknown $(n=8)$.

$43 \%$. All cases showing a prolongation of MTT also showed abnormal elevation of MPAP.

Abnormal findings observed in patients with LBBB without COCM were $90 \%$ by right ventricular biopsy; $72 \%$, by His-BE; $60 \%$, by measurement of MPAP; and $21 \%$ by measurement of MTT.

\section{Discussion}

The purpose of the present work was to correlate the degree of structural changes in COCM to the clinical course in order to get more information on prognosis which can vary considerably. In addition, various clinical, haemodynamic and angiographic data were examined for their prognostic significance. Studies on the possible presymptomatic stage of COCM were also performed.

Calculation of cumulative survival rate from the clinical onset of illness revealed a 10-year mortality rate of $70 \%$ (Fig. 1). More differentiated information on prognosis was obtained by grouping the patients into those with slight changes ( $\leqslant 4$ points) and those with severe structural alterations ( $\geqslant 5$ points) (Fig. 3). Analysis of the morphological picture showed that mainly degenerative changes indicated a worse prognosis in COCM (Fig. 2). Cumulative survival rate from the date of biopsy was then different, i.e. after 4 years it was $54 \%$ and $0 \%$ respectively. These results concerning the prognostic significance of pathological changes were recently confirmed by Bouhour et al. (1976). Other measurements were not significantly different (Table 1). However, grouping the patients regardless of morphological score in a different way (dead or alive) shows a prognostic significance not only of the morphological score but also of the cardiothoracic ratio, EF and LVEDV (Fig. 5). Similar results have also been obtained by other authors (Goodwin and Oakley, 1972; Stapleton et al., 1974). However, the great overlap of data reduces their prognostic usefulness for the individual patient. Best prognostic evaluation seems to be achieved by using all the data together, especially the results of biopsy, cardiothoracic ratio, EF and LVEDV.

EMCB alone seems to be of special prognostic and diagnostic value in patients with short duration of illness (Fig. 4). In these cases (e.g. a sero-negative acute or subacute myocarditis), one cannot with certainty rule out the possibility of a good prognosis. The present data from patients with a duration of illness of $\leqslant 2$ years have provided a new insight into the prognosis for these patients, and it seems even more pronounced for patients with a duration of illness of $<$ one year (Fig. 4). By use of the semiquantitative morphological score, a clear separation was made between those patients with a good prognosis ( $\leqslant 4$ points, 2 -year cumulative mortality rate $14 \%$ ) and those with a very poor prognosis ( $\geqslant 5$ points, 2 -year cumulative mortality rate, $87 \%$ ). Clinical data and haemodynamics of these two groups were different, showing the same tendencies as in the total of all patients.

The extent of pathological change was independent of the duration of illness (Fig. 4). However, one may speculate that the prognostic difference in COCM represents different nosological entities or different speeds of progression of the same disease.

Studies on patients with LBBB were made in order to find a pre-stage of COCM which possibly gives more insight into the course and the aetiology of COCM and would theoretically offer better chances for therapy than the advanced stage of the disease. With regard to their earlier studies in patients with COCM and LBBB (Kuhn et al., 1974, 1978; Loogen and Kuhn, 1977), the authors suggest that a prestage of COCM and a pre-symptomatic and early manifestation of COCM can be present in patients with LBBB and normal LVEDV. This hypothesis is based on the following observations. (1) In agreement with others (Blondeau, 1974, Stapleton et al., 1970) there is a high incidence of complete LBBB in patients with COCM (nearly $40 \%$, Table 4). (2) In 
former prospective and retrospective ECG studies in patients with LBBB and COCM, in no case a common LBBB developed (Kuhn et al., 1974a; Loogen and Kuhn 1977). (3) A high rate of patients with dilated ventricle (COCM, dilated cardiomyopathy) was found in consecutive patients with LBBB, normal heart size and normal coronary arteries (seven out of fifty-two patients, see results). (4) Mean age of patients with LBBB and normal LVEDV (38 years) was lower than mean age of patients with LBBB and COCM (47 years) (Table 4). The significant higher age in COCM with LBBB compared to COCM without LBBB may indicate different aetiological entities. (5) The study of case histories has revealed the existence of LBBB in COCM as far back as 22 years before the onset of signs symptomatic of left heart failure (Table 3). (6) Investigations in patients with LBBB, normal LVEDV and normal coronary arteries revealed a high rate of patients with various abnormalities. Some included abnormal elevation of mean pulmonary artery pressure (MPAP) at exercise $(60 \%$, Figs. 6 and 7) and prolonged minimal cardiac transit times (MTT $(21 \%)$, indicating left heart failure (Vyska et al., 1975; Bonzel et al., 1976; Kuhn et al., 1978; Lösse and Loogen, in press); others included right ventricular morphological changes (total $90 \%$, severe changes $24 \%$ ), indicating a generalized myocardial disorder that apparently is not confined to the conduction system and left ventricle. For these patients (with or without LBBB) with normal LVEDV, normal inter-ventricular septum and normal posterior wall of left ventricle but impaired left ventricular function, mostly demonstrated by abnormal elevated LVEDP (i.e. MPAP), the term 'latent cardiomyopathy (LCM)' is proposed. The designation 'latent' is proposed because in most cases the LVEDP is elevated only on exercise and, because of the observations described above, the pre-existence of COCM in some of the patients may be presumed. The designation cardiomyopathy is based on the unclear aetiology and on the detection of abnormalities in right ventricle from biopsies (Fig. 8). It may be supposed that LCM is an advanced stage of some patients with LBBB alone because the mean age of patients with LCM was significantly higher than that of patients with LBBB without LCM (38 and 48 years, range 28-55 and 31-61 years respectively). Also, EF was lower in these than in those with LBBB without LCM (Fig. 7). A high percentage $(72 \%)$ of abnormal patients with LBBB was detected by His-BE (prolonged HV-time). The interpretation of prolonged $\mathrm{HV}$ interval in LBBB is controversial, but there is much evidence that this finding indicates a diffuse myocardial disorder which is not confined to the conduction system (Seipel, Breithardt and Kuhn, 1978). Of significance was the occurrence of severe microscopic changes in patients with LBBB without LCM, i.e. without signs of impaired left ventricular function (Fig. 8) (five of fortythree patients with LBBB $(24 \%)$, three of them being in the 'LBBB unknown group'); these changes are usually seen only in cases of advanced cardiac hypertrophy corresponding to various experimental and clinical stages of hypertrophied left ventricle (Ferrans et al., 1974, Ferrans, 1978, Kuhn, Pfitzer and Stoepel, 1974b). These may be the result of transient undetected arterial hypertension in some patients with LBBB (Schneider et al., 1976) or from former toxic influences, e.g. diphtheritic heart disease. These severe changes were also observed in a case of rate-dependent LBBB having a completely normal ECG in LBBB-free periods. In further considering the normal haemodynamic and angiographic findings, EMCB seems to be more sensitive for detecting myocardial disorder in these patients.

Taking all these observations on the possible early stage and prognosis of COCM into consideration, pre-symptomatic manifestation or pre-stage of COCM can be suspected in at least some patients with LBBB. These observations are supported by studies (Framingham heart study) reported recently by Schneider et al. (1976) who found that the onset of LBBB was associated in a high percentage with subsequent development of congestive heart failure. The occurrence of severe electronmicroscopic changes in patients with LBBB, indicating a bad prognosis in COCM, or the combination of both LCM and LBBB, possibly indicates subsequent COCM. Therefore, a new indication for performing EMCB emerges. Furthermore, it is possible that LBBB is only a predisposing factor for subsequent COCM, and only with additional 'specific' influences, such as arterial hypertension, virus infection, alcohol or pregnancy will COCM develop (Goodwin and Oakley, 1972; Kuhn and Loogen, 1978). It seems necessary that therapeutic advice by the physician to patients with LBBB considers these aspects especially in those patients with elevated MPAP at exercise and/or severe changes of heart muscle biopsy.

\section{Acknowledgments}

We are grateful for technical assistance to Frl. H. Effertz, Frau M. Krebs, MTA, Frl. B. Renn, MTA, and Frau U. Becker-Lendzian, MTA.

\section{References}

BlondeAU, M. (1974) Le bloque complet de la branche gauche avec forte déviation axiale gauche de QRS. Archives des maladies du coeur, des vaisseaux et du sang, 6, 635 .

Bonzel, T., Schmidt, H., Sigwart, U., Mertens, H.M. \& GleichmanN, U. (1976) Pulmonalarteriendrücke und linksventrikulärer enddiastolischer Druck in Ruhe und unter dynamischer Belastung. Zeitschrift für Kardiologie 64, 1088. 
Bouhour, J.B., Petitier, H., de Lajartre, A.Y., Almanzor, M., Nicolas, G. \& HoreaU, J. (1976) La biopsie myocardique dans les myocardiopathies congestives en apparence primitives. Archives des maladies du coeur, des vaisseaux et du sang, 69, 485.

Breithardt, G., Kuhn, H. \& Knieriem, H.-J. (1978) Prognostic significance of endomyocardial biopsy in patients with congestive cardiomyopathy. In: Cardiomyopathy and Myocardial Biopsy (Ed. by Kaltenbach, M., Loogen, F. \& Olsen, E.G.J.), p. 121, Springer, Berlin-HeidelbergNew York.

CutTer, S.J. \& Ederer, T. (1958) Maximum utilization of the life-table method in analysing survival. Journal of Chronic Diseases, 8, 699.

FERRANS, V.J. (1978) Myocardial ultrastructure in human cardiac hypertrophy. In: Cardiomyopathy and Myocardial Biopsy (Ed. by Kaltenbach, M., Loogen, F \& Olsen, E.G.J.), p. 100, Springer, Berlin-Heidelberg-New York.

Ferrans, V.J., Massumi, R.A., Shugoll, E.J., Ali, N. \& ROBERTS, W.C. (1974) Ultrastructural studies of myocardial biopsies in 45 patients with obstructive or congestive cardiomyopathy. In: Cardiomyopathies (Ed. by Bajusz, E. \& Rona, G.), p. 231, Urban und Schwarzenberg, München.

Goodwin, J.E. \& OAKLeY, C.M. (1972) The cardiomyopathies. British Heart Journal, 34, 545.

Haerten, K., Both, A., Krelhaus, W. \& Loogen, F. (1976) Die Hämodynamik des kleinen Kreislaufs bei Herzgesunden unter mehrstufiger Ergometerbelastung. Medizinische Welt, 27, 2386.

Kuhn, H., Breithardt, L.K., Breithardt, G., Seipel, L. \& Loogen, F. (1974a) Die Bedeutung des Elektrokardiogramms für Diagnose and Verlaufsbeurteilung von Patienten mit congestiver Kardiomyopathie. Zeitschrift für Kardiologie, 63, 916.

Kuhn, H., Breithardt, G., Knieriem, H.-J. \& Loogen, F. (1978) Endomyocardial catheter biopsy in heart disease of unknown etiology. In: Cardiomyopathy and myocardial biopsy (Ed. by Kaltenbach, M., Loogen, F. \& Olsen, E.G.J.), p. 121, Springer, Berlin-Heidelberg-New York.

KuhN, H., Breithardt, G., Knieriem, H.-J., Loogen, F., Both, A., Schmidt, W.A.K., Stroobandt, R. \& GleichMANN, U. (1975) Die Bedeutung der endomyokardialen Katheter Biopsie für die Diagnostik und die Beurteilung der Prognose der congestiven Kardiomyopathie. Deutsche Medizinische Wochenschrift, 100, 717.
Kuhn, H., Kübler, W., Loogen, F. \& GleichmanN, U. (1973) Die congestive Kardiomyopathie. 119. Tagung der Rheinisch-Westfälischen Gesellschaft für Innere Medizin November 1972. Medizinische Welt, 24, 996.

KunN, H. \& Loogen, F. (1978) Die Wirkung des Alkohols auf das Herz einschliesslich der Alkoholkardiomyopathie. Internist, 19, 97.

Kuhn, H., Pfitzer, P. \& Stoepel, K. (1974b) DNA-content and DNA-synthesis in the myocardium of rats after induced renal hypertension. Cardiovascular Research, $8,86$.

Loogen, F. \& KuHN, H. (1977) Classification and natural history of primary cardiomyopathies. In: Myocardial Failure (Ed. by Riecker, G., Weber, A. \& Goodwin, J.F.), p. 232, Springer, Berlin-Heidelberg-New York.

Lösse, B. \& LOOGEN, F. (1978) Left and right ventricular function in patients with myocardial infarction. International Symposium on Latent Cardiac Insufficiency, Venice, April 1977. (In press).

OAKLEY, C.M. (1974) Clinical recognition of the cardiomyopathies. Circulation Research, 34/35 (Suppl. II), 152.

Scherlag, B.J., Lau, S.H., Helfant, R.H., Berkowitz, W.D., Stein, E. \& Damato, A.N. (1969) Catheter technique for recording His-bundle activity in man. Circulation, 39, 13.

SChNeIder, J.F., Thomas, H.E., Kreger, B. \& McNamara, P. (1976) Left bundle branch block in Framingham. Circulation, 54 (Suppl. II), 128.

Seipel, L., Breithardt, G., Kuhn, H. (1978) Left bundle branch block in patients with and without cardiomyopathy. In: Cardiomyopathy and Myocardial Biopsy (Ed. by Kaltenbach, M., Loogen, F. \& Olsen, E.G.J.), p. 237, Springer, Berlin-Heidelberg-New York.

Stapleton, J.F., Segal, J.P. \& Harvey, W.P. (1970) The electro-cardiogram of myocardiopathy. Progress in Cardiovascular Diseases, 13, 217.

Stapleton, J.F., Segal, J.P. \& Harvey, W.P. (1974) Clinical pathway of cardiomyopathy. Circulation $R e^{-}$ search, 34 (Suppl. II), 168.

Vyska, K., Profant, M., Schicha, H., Becker, V., FreundLieb, C. \& FeINENDEgen, L.E. (1975) Theoretische Grundlagen der Anwendung der minimalen kardialen Transitzeiten für die Bestimmung der Ejektions-fraktion in der Herzkammer. In: Nuklearmedizin-Fortschritte der Nuklearmedizin in klinischer und technologischer Sicht (Ed. by Pabst, H.W., Hö, G. \& Schmidt, H.A.E.) p. 68, Schattauer, Stuttgart-New York. 